\title{
Early Postnatal Hypoxia Induces Behavioral Deficits but not Morphological Damage in the Hippocampus in Adolescent Rats
}

\author{
Vladimír RILJAK ${ }^{1}$, Zdeněk LAŠTU゚VKA ${ }^{1}$, Jaromír MYSLIVEČEK ${ }^{1}$, Veronika \\ BORBÉLYOVÁ ${ }^{2}$, Jakub OTÁHAL ${ }^{3}$
}

${ }^{1}$ Institute of Physiology, First Faculty of Medicine, Charles University, Prague, Czech Republic, ${ }^{2}$ Institute of Molecular Biomedicine, Faculty of Medicine, Comenius University, Bratislava, Slovak Republic, ${ }^{3}$ Laboratory of Developmental Epileptology, Institute of Physiology of the Czech Academy of Sciences, Prague, Czech Republic

Received June 14, 2019

Accepted August 23, 2019

Epub Ahead of Print December 19, 2019

\begin{abstract}
Summary
Hypoxia is one of the major pathological factors affecting brain function. The aim of the present study was to describe the effect of neonatal hypobaric hypoxia on the behavior of rats and to analyze its effect on hippocampal neurodegeneration. Hypobaric hypoxia at a simulated altitude of $9000 \mathrm{~m}$ was induced for one hour in neonatal rat pups (PND7 and PND9) of both sexes. Subsequently, the rats underwent behavioral testing on PND25 and PND35 using a LABORAS apparatus to assess spontaneous behavior. Hypoxia did not cause any morphological damage in the hippocampus of rats. However, hypoxia on PND7 led to less horizontal locomotor activity both in males (on PND25) and females (on PND35). Hypoxia on PND9 led to higher rearing in females on PND25. Hypoxic males exhibited higher grooming activity, while females lower grooming activity on PND35 following hypoxia induced on PND7. In females, hypoxia on PND9 resulted in higher grooming activity on PND25. Sex differences in the effect of hypoxia were observed on PND35, when hypoxic males compared to hypoxic females displayed more locomotor, rearing and grooming activity. Our data suggest that hypoxia on PND7 versus PND9 differently affects locomotion and grooming later in adolescence and these effects are sex-dependent.
\end{abstract}

\section{Key words}

Behavior • Hippocampus • Short-term hypoxia • Open field test • Sex differences

\section{Corresponding author}

V. Riljak, Institute of Physiology, First Faculty of Medicine,
Charles University, Prague, Czech Republic. E-mail: vladimir.riljak@lf1.cuni.cz

\section{Introduction}

Hypoxic and hypoxic-ischemic injuries in utero or during birth are major causes of newborn morbidity and mortality. They represent major health concerns in neonatal medicine (Sarnat et al. 1976, Berger et al. 2002, Zayachkivsky et al. 2015). Despite continuous advances in neonatology and intensive care, there is no effective treatment except hypothermia for hypoxia-ischemia (Riljak et al. 2016, Potter et al. 2018). As the immature neonatal brain is highly susceptible and responsive to external and internal stimuli, the timing of hypoxia exposure is an important factor in the severity of behavioral changes (Berger et al. 2002, Cuaycong et al. 2011, Potter et al. 2018). Various animal models of hypoxic and hypoxic-ischemic conditions have been developed to mimic neonatal ischemic and/or hypoxic brain damage (Vannucci 1990, Cuaycong et al. 2011). It has previously been shown that hypoxia-induced behavioral changes (e.g. impaired motor function and novelty recognition) are dependent not only on the timing of hypoxia exposure but also on the intensity of hypoxia (Bona et al. 1998, Carty et al. 2010). Hypoxia interferes with multiple biochemical pathways. These metabolic changes are reflected in brain synaptogenesis, the glial cell response, blood brain barrier permeability and the

PHYSIOLOGICAL RESEARCH • ISSN 1802-9973 (online) 
balance and clearance of neuromediators (Nyakas et al. 1996, Pappas et al. 2015, Potter et al. 2018). Considering these changes, it has been reported that hypoxic episodes during the perinatal period of life can trigger depressionlike behavior (Bogdanova et al. 2014), spatial memory changes (Chen et al. 2018), impaired learning ability (Biswal et al. 2016), excitotoxicity (Ginet et al. 2014) and the induction of cell death in nervous tissue (Arumugam et al. 2018). Previous animal studies have reported that male and female rats are affected by hypoxia differently and show a different extent of behavioral deficits (Hill et al. 2011, Potter et al. 2018). Compared to their female counterparts, male infants exhibit an increased risk of hypoxic-ischemic events and also display greater behavioral and cognitive disruption (Raz et al. 1995, Costeloe et al. 2000, Lauterbach et al. 2001, Donders et al. 2002).

Brain development between postnatal days (PNDs) 7-12 in rats is approximately equivalent to the end of the third trimester of pregnancy in humans (Clancy et al. 2001, Semple et al. 2013). In the present study, we investigated the effect of hypobaric hypoxia at a simulated altitude of $9000 \mathrm{~m}$ on PND7 or PND9 on the spontaneous behavior of young rats during the postweaning period (PND25) and periadolescent period (PND35). Due to the evidence of sex differences in the behavior of neonatal models of hypoxia, both male and female rats were used. In addition, the effect of exposure to early postnatal hypoxia on the severity of brain injury was evaluated, with a focus on morphological changes in the hippocampus using histochemical methods. We hypothesized that the impact of hypoxia would be more severe when applied on PND7 rather than PND9 and that males would display more pronounced behavioral impairments compared to those displayed by females.

\section{Materials and Methods}

\section{Animals and housing conditions}

In the current study, Wistar albino rats $(\mathrm{n}=96$; males $n=48$, females $n=48$ ) were used. The dams were obtained from the Centre for Experimental Biomodels, First Faculty of Medicine, Charles University, Prague and were housed individually. Following the delivery dams were caged with their offspring until weaning on PND21, later on, the offspring was tested as described below.

All rats were kept in a controlled environment (temperature $22 \pm 2{ }^{\circ} \mathrm{C}$, humidity $55 \pm 10 \%$, 12:12-hour light-dark cycle with lights on at 06:00 a.m. and lights off
06:00 p.m.) with ad libitum access to food and water. Behavioral testing took place between 08:00 and 12:00 in a slightly illuminated room with light intensity level 100-120 lux at the level of the cages. All procedures were reviewed and approved by the Institutional Animal Care and Use Committee and were in agreement with the Czech Government Requirements and Requirements of European Communities Council Directive (86/609/EEC). Maximal efforts were made to minimize the suffering of the animals during the experiment.

\section{Simulation of hypobaric hypoxia}

At the age of PND7 (males $n=12$, females $n=12$ ) or PND9 (males $\mathrm{n}=12$, females $\mathrm{n}=12$ ), rat pups of both sexes were exposed to hypobaric hypoxia (apart from their mothers) for $60 \mathrm{~min}$ at a simulated altitude of $9000 \mathrm{~m}(\mathrm{p}=230 \mathrm{~mm} \mathrm{Hg})$. The hypobaric chamber was an airtight box $(60 \times 60 \times 60 \mathrm{~cm})$ equipped with a carbon dioxide sorbent. The time needed to reach the desired altitude was $20 \mathrm{~min}$. The same time was needed to return back to room atmospheric pressure. Following hypoxia exposure, the rat pups were returned to their nest and their mothers until weaning. The number of control rat pups equals to the number of the pups exposed to hypobaric hypoxia. The control groups underwent the same procedure except for the change in atmospheric pressure.

\section{Tissue processing}

For histological analyses, in total 48 rat pups (female: $\mathrm{n}=24$; male: $\mathrm{n}=24$ ) were anaesthetized with an intraperitoneal injection of thiopental $(40 \mathrm{mg} / \mathrm{kg}$ body weight) and were immediately perfused transcardially. The transcardial perfusions were performed $24 \mathrm{~h}$ or 5 days after hypoxia induction (i.e. PND8, PND12, PND10 or PND14, $n=3$ for each gender and time point, one animal served as a control). Another group of rat pups (female: $\mathrm{n}=3$; male: $\mathrm{n}=3$, PND7 and PND9) underwent the same procedure and the transcardial perfusions $24 \mathrm{~h}$ after the last behavioral testing (i.e. PND36). First, ice-cold saline $(0.9 \% \mathrm{NaCl})$ was used for transcardial perfusion, followed by fixation with ice-cold $4 \%$ paraformaldehyde (dissolved in $0.1 \mathrm{M}$ phosphate buffer, pH 7.4). Thereafter, the brain was removed carefully from the cranium of each animal and fixed in $4 \%$ paraformaldehyde overnight. Following fixation, the brains were cryoprotected in $20 \%$ sucrose solution for at least 1 day. 


\section{Detection of neuronal degeneration and apoptosis}

Neuronal degeneration was evaluated histologically in each group of rats using Fluoro-Jade (FJB) and bisbenzimide staining. Bisbenzimide (Hoechst 33342, Sigma-Aldrich, Czech Republic) and FJB (Histo-Chem Inc., USA) co-staining was performed as described previously (Riljak et al. 2007, Riljak et al. 2010). Briefly, the brains were sectioned at $-20{ }^{\circ} \mathrm{C}$ using a cryostat (Leica CM 3050S, Leica Biosystems, Germany), and every third $40-\mu \mathrm{m}$ thick section from each animal brain was collected to assess neuronal degeneration. The tissue sections were then mounted on gelatinized slides (Menzel-Gläser Superfrost Plus, Thermo Scientific, Germany) and allowed to dry at room temperature. Then, the sections were co-stained using FJB and the nuclear counterstain bisbenzimide. The sections were immersed in ethanol, distilled water and potassium permanganate $\left(\mathrm{KMnO}_{4}\right.$, Sigma-Aldrich, Czech Republic). The slides were immersed in a $0.001 \% \mathrm{FJB}$ solution for $30 \mathrm{~min}$ in a dim room with occasional gentle shaking. Thereafter, the sections were immersed in a $0.01 \%$ bisbenzimide staining solution for $10 \mathrm{~min}$, dehydrated, coverslipped using DPX neutral mounting medium (Neo-Mount, Merck, Germany) and allowed to dry. The sections were visualized using an epifluorescence microscope (Olympus AX 70 Provis, Olympus, Czech Republic) with appropriate filter settings for blue and green fluorescence. The following regions of brain tissue were analysed for neuronal degeneration or apoptosis: the CA1 and CA3 regions of the hippocampus, the hilus, and the dorsal and ventral blades of the dentate gyrus. The presence of FJB-positive cells was determined in each of the above listed regions of the hippocampus.

\section{Nissl staining}

Each fourth coronal section of the brain (obtained as described above in sections 2.3. and 2.4.) was stained with cresyl violet (Sigma-Aldrich, Czech Republic). The mounted brain tissue sections were dehydrated in a graded series of ethanol $(70 \%, 80 \%$, $96 \%$ ) for 2 min each and then stained with Nissl solution ( $1 \%$ cresyl violet, $0.2 \mathrm{~mol} / 1$ acetic acid, and $0.2 \mathrm{~mol} / 1$ sodium acetate, $4: 1, \mathrm{pH}=3$ ) for approximately $20 \mathrm{~min}$. When the desired color intensity was reached, the slices were washed twice in distilled water and in a graded series of ethanol $(96 \%, 80 \%, 70 \%)$ for 2 min each. The slides were then immersed in xylene (Penta, Czech Republic) for $5 \mathrm{~min}$. Subsequently, the slides were incubated in another xylene bath (for approximately
$45 \mathrm{~min}$ ) and were mounted with Roti-Histokitt II mounting medium (Roth, Germany) and coverslipped.

\section{Behavioral testing}

Open field test (LABORAS system)

For behavioral testing in total 48 rat pups were used (males $\mathrm{n}=24$, females $\mathrm{n}=24$ ). LABORAS is an automated system for the continuous tracking of small rodent behavior. On PND25 and PND35, the spontaneous behavior of the animals was analysed. The animals were weighed and placed in the LABORAS system, and the behavior of the animals was monitored for $1 \mathrm{~h}$. The LABORAS system transforms the mechanical vibrations generated by the animal (during locomotion, rearing, grooming, etc.) into electrical signals. These signals are processed, classified and compared with predetermined characteristic patterns by LABORAS software (Van de Weerd et al. 2001). Spontaneous behavior was analysed over successive 10-min intervals (0-10 min, $10-20 \mathrm{~min}$, 20-30 min, 30-40 min, 40-50 min, 50-60 min). Each recorded behavioral parameter, such as the time spent in locomotion, the time spent rearing, the time spent grooming and the distance travelled, was evaluated separately. Throughout the one-hour sessions, the animals were left undisturbed. Following the behavioral testing, the animals were returned to their home cages. On PND35, all animals were retested as described above.

\section{Statistical analysis}

Statistical analysis was performed using GraphPad Prism version 7 (GraphPad Software, Inc., CA, USA). To analyze the spontaneous behavior of the rats and detect sex differences, two-way analysis of variance (ANOVA) with Bonferroni-corrected post hoc $t$-test was used. $\mathrm{p}<0.05$ were considered statistically significant. The data are presented as the mean \pm standard error of the mean (SEM).

\section{Results}

\section{Locomotor activity in rats exposed to hypoxia on PND7}

\section{Open field test performed on PND25}

Regarding the distance travelled by the males (Fig. 1A), two-way ANOVA indicated a main effect of treatment $\left[\mathrm{F}_{(1,67)}=14.7, \mathrm{p}<0.001\right]$ and time $\left[\mathrm{F}_{(5,67)}=90.5\right.$, $\mathrm{p}<0.001]$. The interaction between these two factors was not significant $\left[\mathrm{F}_{(5,67)}=1.52, \mathrm{p}=0.2\right]$. Significant effects of 
treatment $\left[\mathrm{F}_{(1,72)}=7.17, \mathrm{p}<0.01\right]$ and time $\left[\mathrm{F}_{(5,72)}=71.4\right.$, $\mathrm{p}<0.001]$ on locomotion duration (Fig. 1C) were revealed using two-way ANOVA. The time $\mathrm{x}$ treatment interaction was not significant $\left[\mathrm{F}_{(5,72)}=1.27, \mathrm{p}=0.29\right]$. Compared to the controls, the hypoxic male rats travelled a shorter distance (by $24 \%, \mathrm{t}_{(67)}=3.34, \mathrm{p}<0.01$ ) and spent less time in locomotion (by $23 \%, \mathrm{t}_{(72)}=2.94, \mathrm{p}<0.05$ ) in the first $10 \mathrm{~min}$ of the test. A main effect of time $\left[\mathrm{F}_{(5,72)}=22.7\right.$, $\mathrm{p}<0.001]$ but not of treatment $\left[\mathrm{F}_{(1,72)}=3.17, \mathrm{p}=0.08\right]$ on the rearing activity of the males (Fig. 1E) was found using two-way ANOVA. The interaction between these two factors was not significant $\left[\mathrm{F}_{(5,72)}=1.18, \mathrm{p}=0.33\right]$.

Regarding the locomotor activity of the females (the distance travelled, Fig. 1B), two-way ANOVA showed a significant effect of time $\left[\mathrm{F}_{(5,72)}=37, \mathrm{p}<0.001\right]$ but not of treatment $\left[\mathrm{F}_{(1,72)}=0.07, \mathrm{p}=0.8\right]$. The time $\mathrm{x}$ treatment interaction was not significant $\left[\mathrm{F}_{(5,72)}=0.47\right.$, $\mathrm{p}=0.8]$. A main effect of time was observed on the locomotion duration of the females $\left[\mathrm{F}_{(5,72)}=33.3, \mathrm{p}<0.001\right.$, Fig. 1D]. The effect of treatment $\left[\mathrm{F}_{(1,72)}=0.003, \mathrm{p}=0.95\right]$ and the interaction between these two factors was insignificant $\left[\mathrm{F}_{(5,72)}=0.73, \mathrm{p}=0.60\right]$. In the case of rearing duration (Fig. 1F), two-way ANOVA showed a main effect of time $\left[F_{(5,72)}=22.9, p<0.001\right]$ but not of treatment $\left[\mathrm{F}_{(1,72)}=0.12, \mathrm{p}=0.73\right]$. The time $\mathrm{x}$ treatment interaction was also not significant $\left[\mathrm{F}_{(5,72)}=1.48, \mathrm{p}=0.2\right]$. The Bonferroni-corrected post hoc $t$-test did not show significant differences in either horizontal (distance travelled and the duration of locomotion) or vertical (rearing duration) locomotor activity in the females.
PND25 after PND7 hypoxia

$\square$ Male Control $\quad$ Male Hypoxia $\quad$ Female Control
๑ Female Hypoxia

\section{Distance travelled}
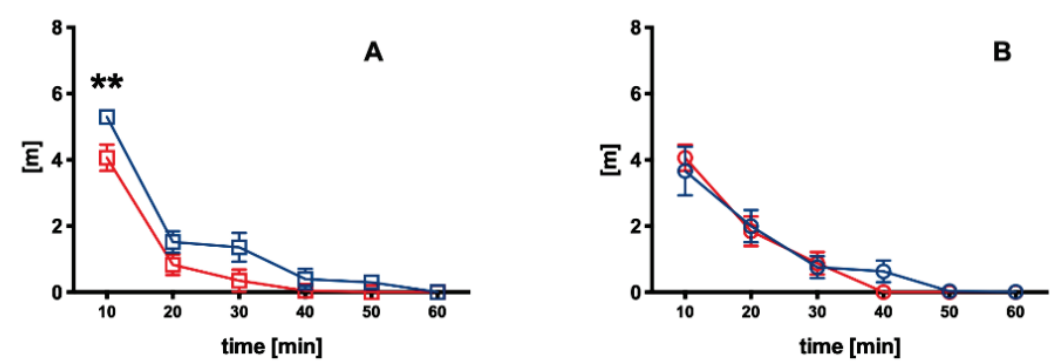

Locomotion duration

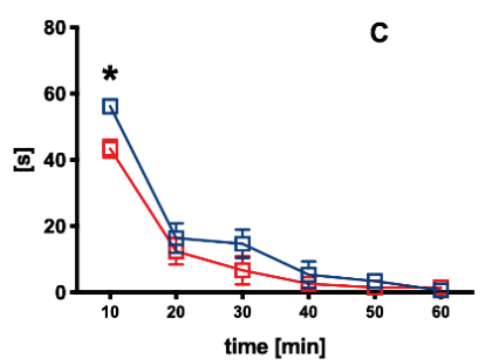

Rearing duration

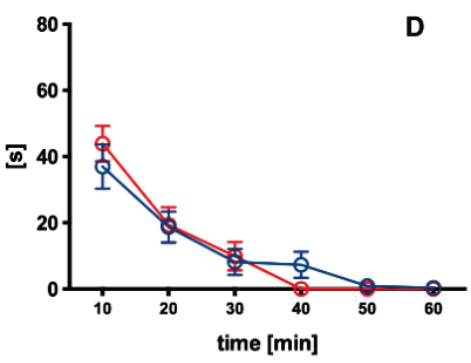

E
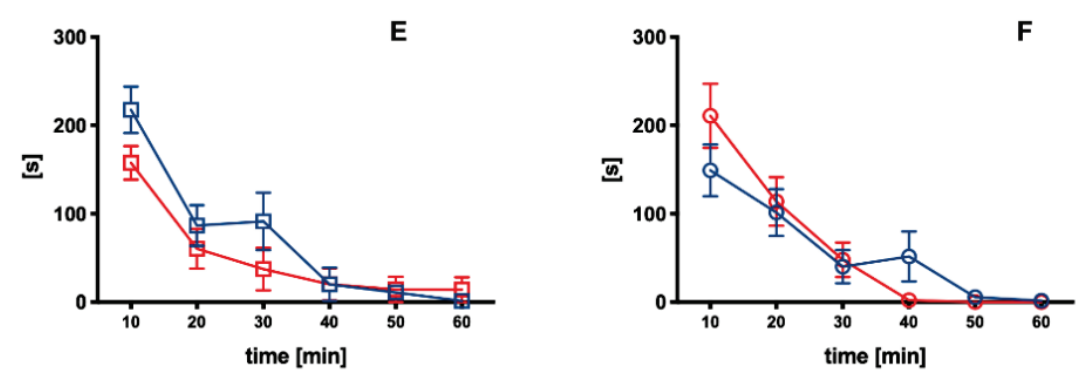

Fig. 1. Locomotor activity of male $(n=12)(\mathbf{A}, \mathbf{C}, \mathbf{E})$ and female $(n=12)$ (B, D, F) pups on PND25 following hypoxia exposure on PND7. Panels A and $\mathrm{B}$ show the distance travelled, $C$ and $D$ show the locomotion duration and $E$ and $F$ show the rearing duration (verticalisation) in a particular 10-minute interval. PND - postnatal day, ${ }^{*} p<0.05,{ }^{* *} p<0.01$. The data are presented as the mean \pm SEM. 


\section{Open field test performed on PND35}

In the males, two-way ANOVA showed a significant effect of time on every observed parameter during the testing period [distance travelled: $\mathrm{F}_{(5,72)}=27.6$, $\mathrm{p}<0.001$, Fig. $2 \mathrm{~A}$; the duration of locomotion: $\mathrm{F}_{(5,72)}=30$, $p<0.001$, Fig. $2 C$; rearing duration: $F_{(5,72)}=22.9, p<0.001$, Fig. 2E]. However, no effect of treatment on the distance travelled $\left[\mathrm{F}_{(1,72)}=0.14, \mathrm{p}=0.7\right.$, Fig. $\left.2 \mathrm{~A}\right]$, duration of locomotion $\left[\mathrm{F}_{(1,72)}=0.15, \mathrm{p}=0.7\right.$, Fig. $\left.2 \mathrm{C}\right]$ or rearing $\left[F_{(1,72)}=0.008, p=0.92\right.$, Fig. $\left.2 E\right]$ was found. The treatment $\mathrm{x}$ time interaction was not significant for any of the observed parameters [distance travelled: $\mathrm{F}_{(5,72)}=0.4$, $\mathrm{p}=0.85$, Fig. $2 \mathrm{~A}$; duration of locomotion: $\mathrm{F}_{(5,72)}=0.43$, $\mathrm{p}=0.83$, Fig. $2 \mathrm{C}$; rearing duration: $\mathrm{F}_{(5,72)}=0.24, \mathrm{p}=0.94$, Fig. 2E]. The Bonferroni-corrected post hoc $t$-test showed no significant differences in these behavioral parameters. In the females, a main effect of both treatment $\left[\mathrm{F}_{(1,72)}=4.97, \mathrm{p}<0.05\right]$ and time $\left[\mathrm{F}_{(5,72)}=25.94, \mathrm{p}<0.001\right]$ on the distance travelled was shown by two-way ANOVA. The treatment $\mathrm{x}$ time interaction was significant $\left[F_{(5,72)}=4.43, p<0.01\right.$, Fig. $\left.2 B\right]$. The hypoxic females moved less than the control females during the first $20 \mathrm{~min}$ of the testing period $\left(1^{\text {st }} 10 \mathrm{~min}\right.$ session: by $37 \%$, $\mathrm{t}_{(72)}=2.96, \mathrm{p}<0.05 ; 2^{\text {nd }} 10 \mathrm{~min}$ session: by $65 \%, \mathrm{t}_{(72)}=3.91$, $\mathrm{p}<0.01$, Fig. 2B). Two-way ANOVA revealed a significant effect of time but not of treatment on both the duration of locomotion [time: $\mathrm{F}_{(5,72)}=26.3, \mathrm{p}<0.001$; treatment: $F_{(1,72)}=1.18, p=0.18$, Fig. $\left.2 \mathrm{D}\right]$ and rearing [time: $\mathrm{F}_{(5,72)}=16.34, \mathrm{p}<0.001$; treatment: $\mathrm{F}_{(1,72)}=0.87$, $\mathrm{p}=0.36$, Fig. $2 \mathrm{~F}]$. The hypoxic females spent less time in locomotion (by $43 \%$ ) than control females, an effect seen only during the $2^{\text {nd }} 10 \mathrm{~min}$ session of open field testing $\left(\mathrm{t}_{(72)}=2.8, \quad \mathrm{p}<0.05\right.$, Fig. 2D). The time $\mathrm{x}$ treatment interaction was not significant for either the duration of locomotion $\left[\mathrm{F}_{(5,72)}=3.14, \mathrm{p}=0.01\right.$, Fig. $\left.2 \mathrm{D}\right]$ or rearing $\left[\mathrm{F}_{(5,72)}=2.13\right.$, $\mathrm{p}=0.07$, Fig. $\left.2 \mathrm{~F}\right]$.

\section{PND35 after PND7 hypoxia}

๑ Male Control $\square$ Male Hypoxia $\oslash$ Female Control $\vartheta$ Female Hypoxia

\section{Distance travelled}

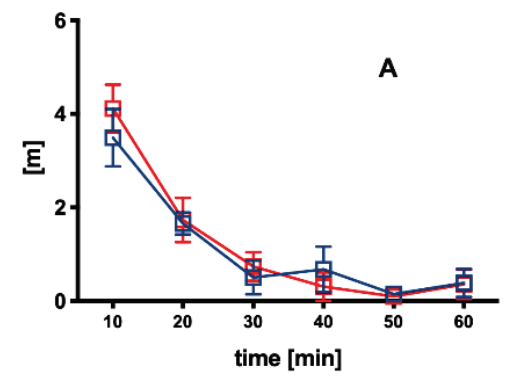

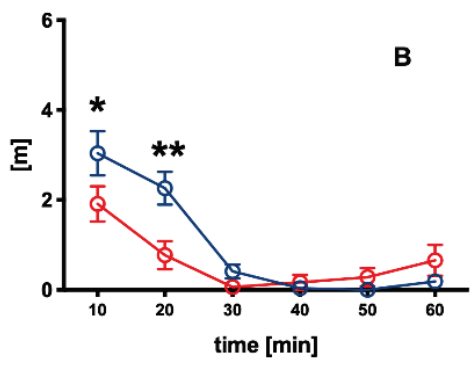

Fig. 2. Locomotor activity of male $(n=12)(\mathbf{A}, \mathbf{C}, \mathbf{E})$ and female $(n=12)$ (B, D, F) pups on PND35 following hypoxia exposure on PND7. Panels $A$ and $\mathrm{B}$ illustrate the distance travelled, $C$ and $D$ illustrate the locomotion duration and $\mathrm{E}$ and $\mathrm{F}$ illustrate the rearing duration (verticalisation) in a particular 10-minute interval. PND postnatal day, ${ }^{*} p<0.05,{ }^{* *} p<0.01$. The data are presented as the mean \pm SEM.
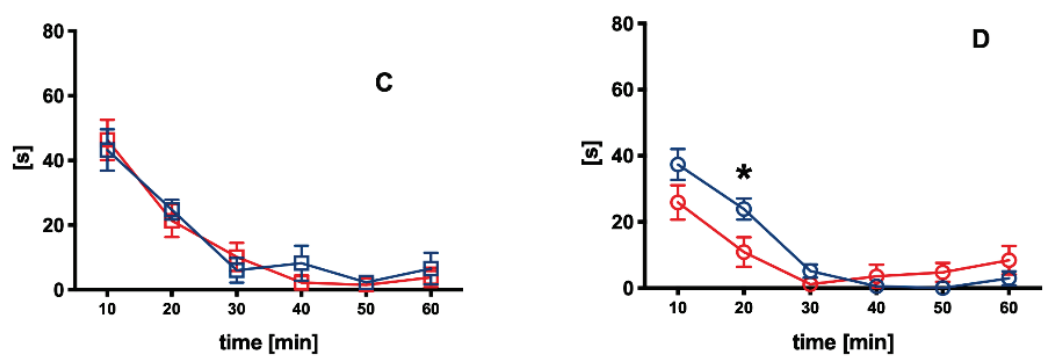

Rearing duration
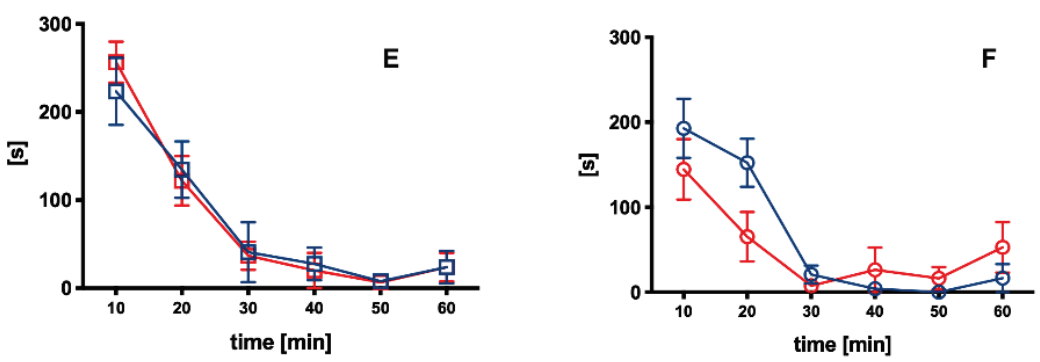


\section{Locomotor activity in rats exposed to hypoxia on PND9}

\section{Open field test performed on PND25}

Regarding the distance travelled by the males (Fig. 3A), two-way ANOVA indicated a main effect of time $\left[\mathrm{F}_{(5,48)}=4.59, \mathrm{p}<0.01\right]$ but not of treatment $\left[\mathrm{F}_{(1,48)}=1.4, \mathrm{p}=0.24\right]$. The interaction between these two factors was also not significant $\left[\mathrm{F}_{(5,48)}=0.76, \mathrm{p}=0.58\right]$. Two-way ANOVA confirmed a significant effect of time $\left[\mathrm{F}_{(5,48)}=3.87, \mathrm{p}<0.01\right]$ and an insignificant effect of treatment $\left[\mathrm{F}_{(1,48)}=2.37, \mathrm{p}=0.13\right]$ on locomotion duration (Fig. 3C) in the males. The time $\mathrm{x}$ treatment interaction was not significant $\left[\mathrm{F}_{(5,48)}=0.49, \mathrm{p}=0.79\right]$. No effect of time $\left[\mathrm{F}_{(5,48)}=1.27, \mathrm{p}=0.29\right]$, treatment $\left[\mathrm{F}_{(1,48)}=2.67, \mathrm{p}=0.1\right]$ or the interaction between them $\left[\mathrm{F}_{(5,48)}=0.87, \mathrm{p}=0.51\right]$ on rearing activity in the male offspring was found (Fig. 3E).
Regarding the locomotor activity of the females (distance travelled, Fig. 3B), two-way ANOVA showed a significant effect of both time $\left[\mathrm{F}_{(5,48)}=14.85, \mathrm{p}<0.001\right]$ and treatment $\left[\mathrm{F}_{(1,48)}=5.17, \mathrm{p}<0.05\right]$. The time $\mathrm{x}$ treatment interaction was not significant $\left[\mathrm{F}_{(5,48)}=0.88, \mathrm{p}=0.5\right]$. The Bonferroni-corrected post hoc $t$-test did not show any significant differences. A main effect of treatment and time on the locomotion duration of the females [treatment: $\mathrm{F}_{(1,48)}=5.79, \mathrm{p}<0.05$; time: $\mathrm{F}_{(5,48)}=18.29$, $\mathrm{p}<0.001$, Fig. 3D] was observed. The interaction of these two factors was insignificant $\left[\mathrm{F}_{(5,48)}=0.87, \mathrm{p}=0.5\right]$. The Bonferroni-corrected post hoc $t$-test did not show any significant differences. In the case of rearing duration (Fig. 3F), two-way ANOVA showed a main effect of time $\left[\mathrm{F}_{(5,48)}=9.66, \mathrm{p}<0.001\right]$ and treatment $\left[\mathrm{F}_{(1,48)}=9.3\right.$, $\mathrm{p}<0.01]$. The time $\mathrm{x}$ treatment interaction was not
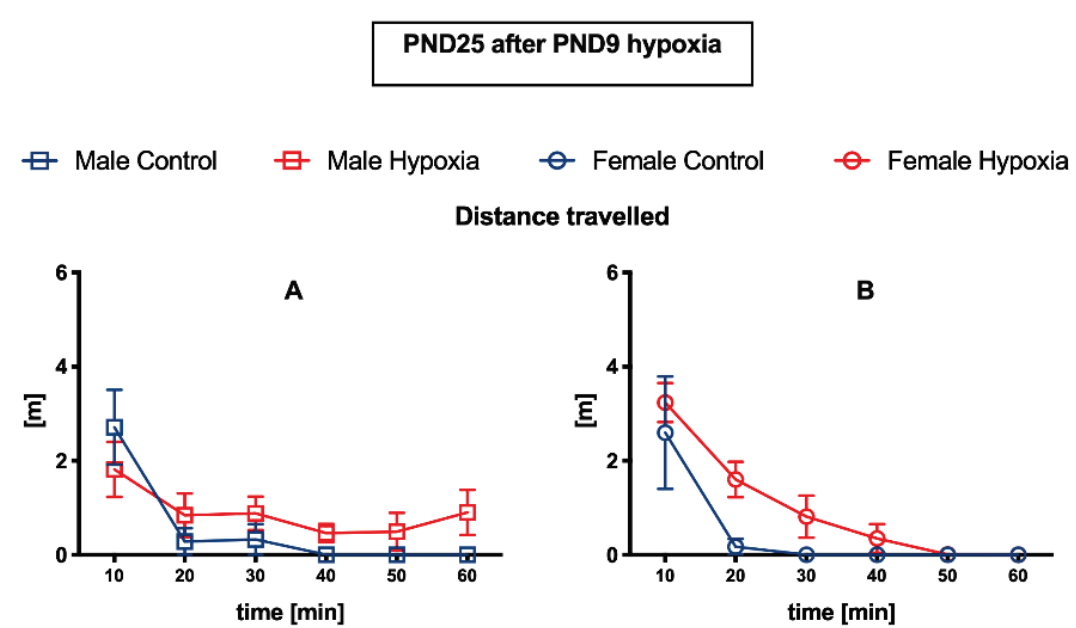

Locomotion duration

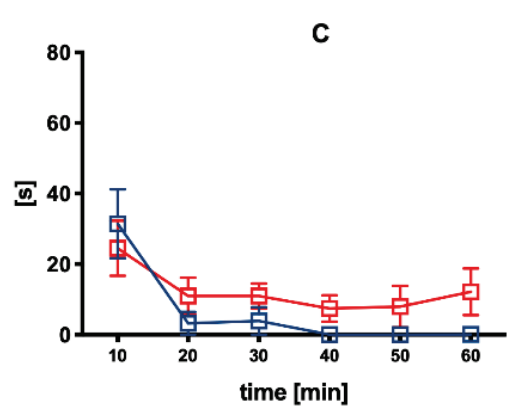

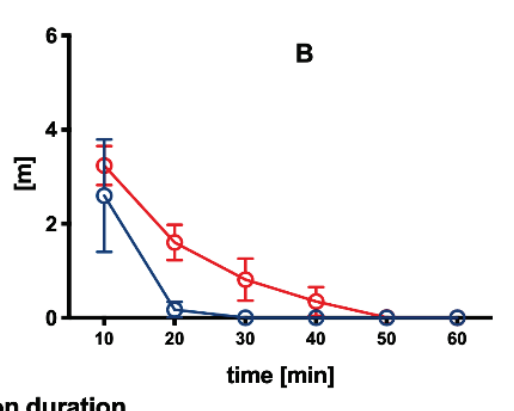

D

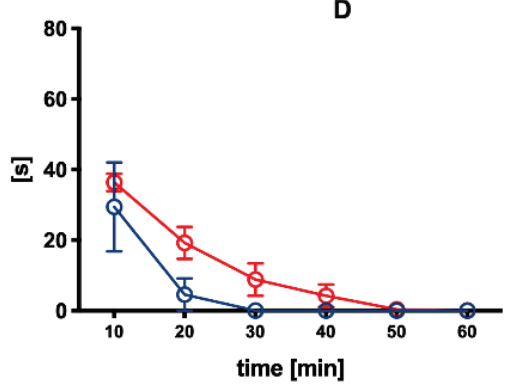

Fig. 3. Locomotor activity of male $(n=12)(\mathbf{A}, \mathbf{C}, \mathbf{E})$ and female $(n=12)$ (B, D, F) pups on PND25 following hypoxia exposure on PND9. Panels A and $\mathrm{B}$ illustrate the distance travelled, $C$ and $D$ illustrate the locomotion duration and $\mathrm{E}$ and $\mathrm{F}$ illustrate the rearing duration (verticalisation) in a particular 10-minute interval. PND - postnatal day, ${ }^{*} p<0.05$. The data are presented as the mean \pm SEM.

\section{Rearing duration}
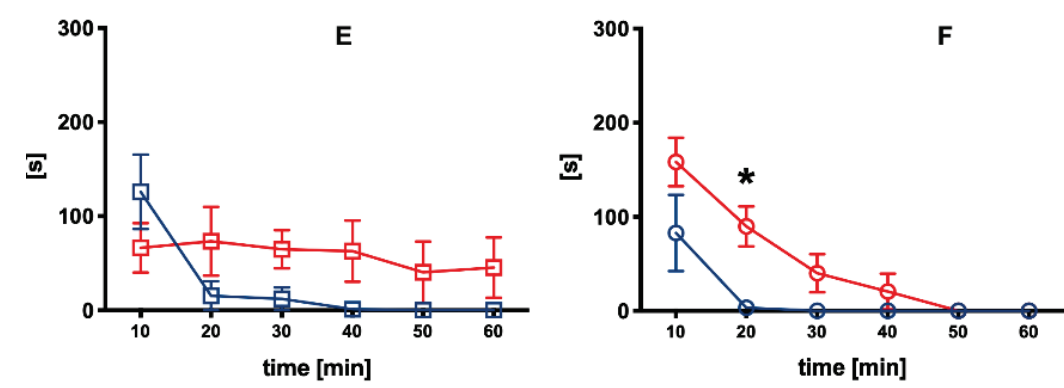
significant $\left[\mathrm{F}_{(5,48)}=1.56, \mathrm{p}=0.19\right]$. The Bonferronicorrected post hoc t-test showed significant differences in vertical locomotor activity (a more than 20-times longer rearing duration in the hypoxic females) in the females in the $20^{\text {th }}$ minute $\left[\mathrm{t}_{(48)}=2.9, \mathrm{p}<0.05\right]$.

\section{Open field test performed on PND35}

Two-way ANOVA revealed a main effect of time $\left[\mathrm{F}_{(5,54)}=22.2, \mathrm{p}<0.001\right.$, Fig. $\left.4 \mathrm{~A}\right]$ but not of treatment $\left[\mathrm{F}_{(1,54)}=0.29, \mathrm{p}=0.59\right]$ on horizontal locomotor activity in the males. The interaction between these two factors was also not significant $\left[\mathrm{F}_{(5,54)}=0.46, \mathrm{p}=0.8\right]$. Similarly, regarding locomotor activity duration in the males, a main effect of time $\left[\mathrm{F}_{(5,54)}=30.9, \mathrm{p}<0.001\right]$, but not of treatment, was observed $\left[\mathrm{F}_{(1,54)}=0.61, \mathrm{p}=0.44\right]$. The treatment $\mathrm{x}$ time interaction was insignificant $\left[F_{(5,54)}=0.73, p=0.61\right.$, Fig. $\left.4 C\right]$. There was a main effect of time $\left[\mathrm{F}_{(5,54)}=15.53, \mathrm{p}<0.001\right]$ but not of treatment $\left[\mathrm{F}_{(1,54)}=1.08, \mathrm{p}=0.30\right]$ on the rearing activity of males. The treatment $\mathrm{x}$ time interaction was not significant $\left[F_{(5,54)}=0.47, p=0.80\right.$, Fig. $\left.4 \mathrm{E}\right]$. The females behaved in a similar way (Fig. 4B, 4D, 4F); for all tested parameters, the only significant effect observed was the effect of time [distance travelled: $\mathrm{F}_{(5,42)}=22.7, \mathrm{p}<0.001$; locomotion duration: $\mathrm{F}_{(5,42)}=15.14, \mathrm{p}<0.001$; rearing duration: $\left.\mathrm{F}_{(5,54)}=18.9, \mathrm{p}<0.001\right]$. No significant effect of treatment was detected on the distance travelled $\left[\mathrm{F}_{(1,42)}=0.001\right.$, $\mathrm{p}=0.97]$, the locomotion duration $\left[\mathrm{F}_{(1,42)}=0.74, \mathrm{p}=0.39\right]$ or the rearing duration $\left[\mathrm{F}_{(1,42)}=0.44, \mathrm{p}=0.51\right]$. The time $\mathrm{x}$ treatment interaction was not significant for any of the

\section{PND35 after PND9 hypoxia}

\# Male Control $\quad$ Male Hypoxia $\theta$ Female Control $\theta$ Female Hypoxia
Distance travelled

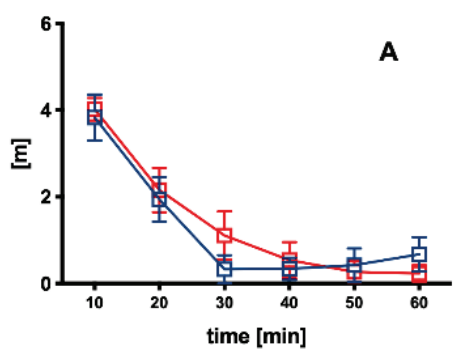

B

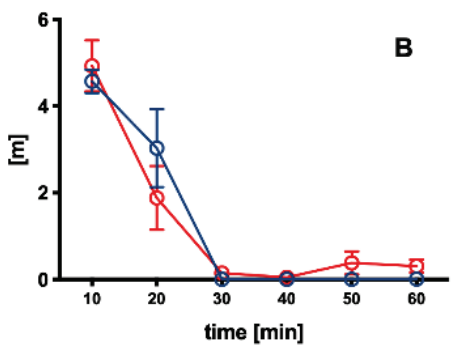

Fig. 4. Locomotor activity of male $(n=12)(\mathbf{A}, \mathbf{C}, \mathbf{E})$ and female $(n=12)$ (B, D, F) pups on PND35 following hypoxia exposure on PND9. Panels A and $\mathrm{B}$ show the distance travelled, $C$ and $D$ illustrate the duration of locomotion and $\mathrm{E}$ and $\mathrm{F}$ show the duration of rearing (verticalisation) in a particular 10-minute interval. PND postnatal day. The data are presented as the mean \pm SEM.

Locomotion duration
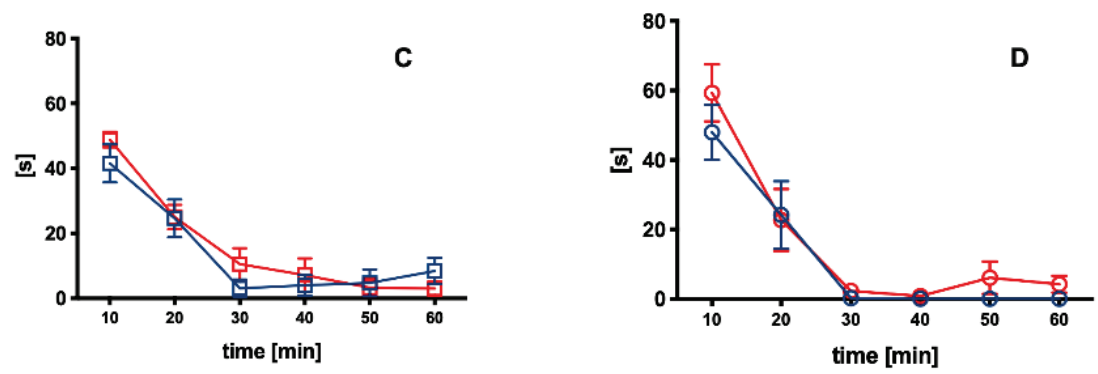

Rearing duration
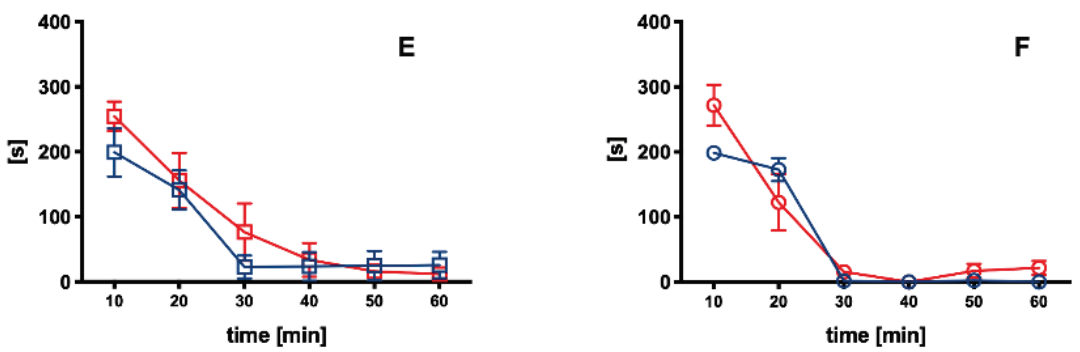
observed parameters [distance travelled: $\mathrm{F}_{(5,42)}=0.5$, $\mathrm{p}=0.77$; locomotion duration: $\mathrm{F}_{(5,42)}=0.17, \mathrm{p}=0.97$; rearing duration: $\left.\mathrm{F}_{(5,42)}=0.76, \mathrm{p}=0.58\right]$.

\section{Effect of early postnatal hypoxia on grooming activity} in rats in the open field test

Grooming activity of the rats exposed to hypoxia on PND7

In the open field test performed on PND25 (Fig. 5A, 5B), two-way ANOVA indicated the main effect of time on grooming activity in both sexes [male: $\mathrm{F}_{(5,71)}=5.41, \mathrm{p}<0.01$, Fig. 5A; female: $\mathrm{F}_{(5,72)}=7.14, \mathrm{p}<0.001$,
Fig. 5B]. The effect of treatment was not significant either in females $\left[\mathrm{F}_{(1,72)}=0.68, \mathrm{p}=0.41\right]$ or males $\left[\mathrm{F}_{(1,71)}=1.07\right.$, $\mathrm{p}=0.3]$. Similarly, the treatment $\mathrm{x}$ time interaction was insignificant [males: $\mathrm{F}_{(5,71)}=0.46, \mathrm{p}=0.8$; females $\left.\mathrm{F}_{(5,72)}=1.47, \mathrm{p}=0.21\right]$.

When the males were retested on PND35 (Fig. 5C), significant effects of all factors were observed [time: $\mathrm{F}_{(5,72)}=5.26, \mathrm{p}<0.001$; treatment: $\mathrm{F}_{(1,72)}=4.98, \mathrm{p}<0.05$; time $\mathrm{x}$ treatment interaction: $\left.\mathrm{F}_{(5,72)}=2.87, \mathrm{p}<0.05\right]$. The Bonferroni-corrected post hoc $t$-test showed that the hypoxic males spent significantly more time grooming (a five-fold increase relative to the controls) $\left[\mathrm{t}_{(72)}=3.99\right.$, $\mathrm{p}<0.001$ ] between the $20^{\text {th }}$ and $30^{\text {th }}$ minute. A main effect
๑ Male Control $\quad$ Male Hypoxia $\ominus$ Female Control $\ominus$ Female Hypoxia

\section{PND25 after PND7 hypoxia}
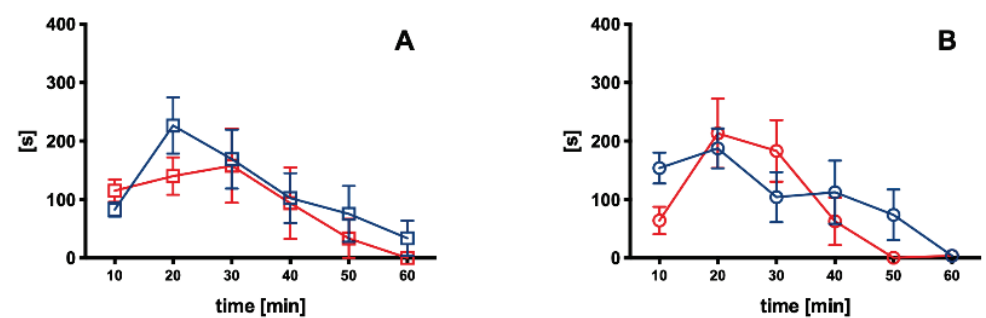

PND35 after PND7 hypoxia
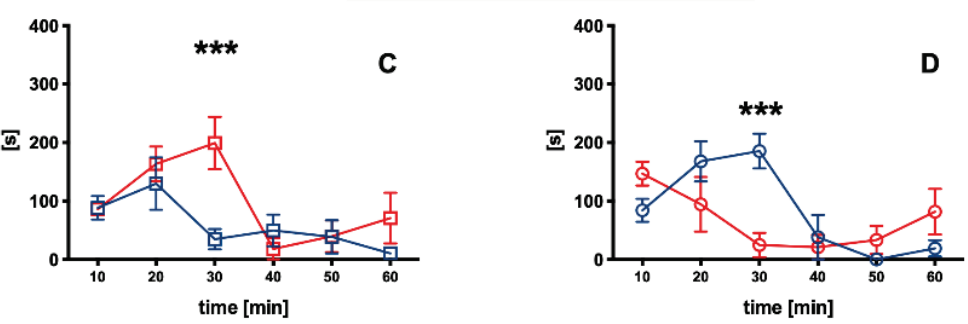

PND25 after PND9 hypoxia
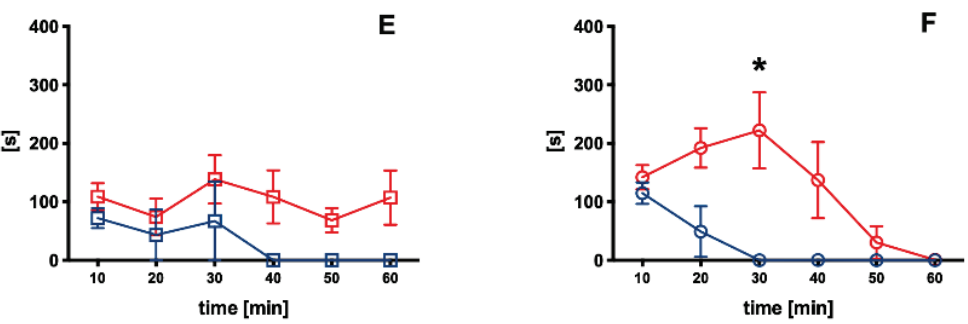

PND35 after PND9 hypoxia
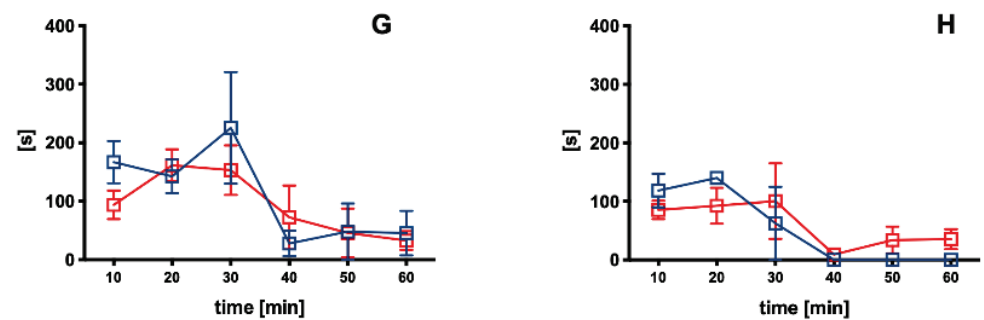

Fig. 5. Grooming activity of male $(n=12) \quad(\mathbf{A}, \mathbf{C}, \mathbf{E}, \mathbf{G})$ and female $(n=12)(B, D, F, \mathbf{H})$ pups exposed to hypoxia on PND7 or PND9. Panels A and $B$ show the grooming activity on PND25 of the pups exposed to hypoxia on PND7; $C$ and D show the grooming duration on PND35 of the pups exposed to hypoxia on PND7; $E$ and $F$ illustrate the grooming duration on PND25 of the pups exposed to hypoxia on PND9; and $\mathrm{G}$ and $\mathrm{H}$ show the grooming duration on PND35 of the pups exposed to hypoxia on PND9. PND - postnatal day, ${ }^{*} p<0.05,{ }^{* * *} p<0.001$. The data are presented as the mean \pm SEM. 
of time $\left[\mathrm{F}_{(5,72)}=5.8, \quad \mathrm{p}<0.001\right]$ but not of treatment $\left[\mathrm{F}_{(1,72)}=0.88, \mathrm{p}=0.35\right]$ and a significant interaction of these two factors $\left[\mathrm{F}_{(5,72)}=4.83, \mathrm{p}<0.001\right]$ on grooming activity were observed on PND35 in the females (Fig. 5D). The Bonferroni-corrected post hoc $t$-test revealed significantly lower grooming activity in the hypoxic females (by $87 \%$ ) than in the controls between the $20^{\text {th }}$ and $30^{\text {th }}$ minute of the open field test $\left[\mathrm{t}_{(72)}=4.0, \mathrm{p}<0.001\right]$.

Grooming activity of the rats exposed to hypoxia on PND9

On PND25, two-way ANOVA yielded the following results for the males (Fig. 5E): the effect of treatment was significant $\left[\mathrm{F}_{(1,48)}=8.08, \mathrm{p}<0.01\right]$, and the effect of time $\left[\mathrm{F}_{(5,48)}=0.72, \mathrm{p}=0.61\right]$ and the interaction between these factors $\left[\mathrm{F}_{(5,48)}=0.3, \mathrm{p}=0.91\right]$ were not significant. In contrast, in the females (Fig. 5F), the effect of time $\left[F_{(5,48)}=2.66, p<0.05\right]$ and the effect of treatment $\left[\mathrm{F}_{(5,48)}=11.29, \mathrm{p}<0.01\right]$ were both significant, and the interaction between these factors was not significant $\left[\mathrm{F}_{(5,48)}=1.63, \mathrm{p}=0.17\right]$. The Bonferroni-corrected post hoc $t$-test showed that the hypoxic females engaged in grooming significantly more than the control females between the $20^{\text {th }}$ and $30^{\text {th }} \min \left[\mathrm{t}_{(48)}=3.26, \mathrm{p}<0.05\right]$. On PND35, in the males, the main effect of time $\left[\mathrm{F}_{(5,54)}=4.29\right.$, $\mathrm{p}<0.01]$ but not of treatment $\left[\mathrm{F}_{(1,54)}=0.41, \mathrm{p}=0.52\right]$ was found, and the time $\mathrm{x}$ treatment interaction $\left[\mathrm{F}_{(5,54)}=0.6\right.$, $\mathrm{p}=0.7]$ was not significant (Fig. 5G). The Bonferronicorrected post hoc $t$-test did not show any significant differences between the hypoxic and control males. According to the ANOVA results, the hypoxic females did not significantly differ from the controls [Fig. $5 \mathrm{H}$; time: $\mathrm{F}_{(5,42)}=2.3, \mathrm{p}=0.06$; treatment: $\mathrm{F}_{(1,42)}=0.05, \mathrm{p}=0.82$; time $\mathrm{x}$ treatment interaction: $\left.\mathrm{F}_{(5,42)}=0.34, \mathrm{p}=0.89\right]$.

Sexually dimorphic behavioral outcomes of early postnatal hypoxia

An additional aim of the present study was to describe the sex differences in the effects of early postnatal hypoxia on the behavior of offspring. To detect these sex differences in the hypoxic animals, two-way ANOVA with sex (male/female) and time (0-10, 10-20, 30-40, 40-50, $50-60 \mathrm{~min})$ as the factors was performed.

Sex differences in the behavior of rats following early postnatal hypoxia on PND7

In the open field test conducted on PND25 (data not shown, see supplementary material), the comparison of the recorded behavioral parameters of the hypoxic males and females confirmed only the main effect of time on all observed outcomes [distance travelled: $\mathrm{F}_{(5,67)}=71.1$, $\mathrm{p}<0.001$; locomotion duration: $\mathrm{F}_{(5,72)}=53.2, \mathrm{p}<0.001$; rearing duration: $\mathrm{F}_{(5,72)}=25.2, \mathrm{p}<0.001$; grooming activity: $\left.\mathrm{F}_{(5,71)}=6.70, \mathrm{p}<0.001\right]$. The effect of sex was not significant [distance travelled: $\mathrm{F}_{(1,67)}=2.50, \mathrm{p}=0.12 ;$ locomotion duration: $\mathrm{F}_{(1,72)}=0.22, \mathrm{p}=0.64$; rearing duration: $\mathrm{F}_{(1,72)}=1.08$, $\mathrm{p}=0.30$; grooming: $\left.\mathrm{F}_{(1,71)}=0.008, \mathrm{p}=0.93\right]$. The sex $\mathrm{x}$ time interaction was not significant for any of the observed parameters [distance travelled: $\mathrm{F}_{(5,67)}=1.24, \mathrm{p}=0.30$; locomotion duration: $\mathrm{F}_{(5,72)}=0.63, \mathrm{p}=0.68$; rearing duration: $\mathrm{F}_{(5,72)}=1.47, \mathrm{p}=0.21$; grooming activity: $\mathrm{F}_{(5,71)}=0.67$, $\mathrm{p}=0.65]$.

On PND35 (data not shown, see supplementary material), two-way ANOVA confirmed significant effects of $\operatorname{sex}\left[\mathrm{F}_{(1,72)}=9.99, \mathrm{p}<0.01\right]$ and time $\left[\mathrm{F}_{(5,72)}=23.3\right.$, $\mathrm{p}<0.001]$ and a significant sex $\mathrm{x}$ time interaction $\left[\mathrm{F}_{(5,72)}=4.28, \mathrm{p}<0.01\right]$ on the distance travelled in the open field test. Similarly, a main effect of both sex and time [sex: $F_{(1,72)}=5.05, p<0.05$; time: $\left.F_{(5,72)}=21.45, p<0.001\right]$ on locomotion duration was revealed. The interaction of these two factors was also significant $\left[\mathrm{F}_{(5,72)}=3.12, \mathrm{p}<0.05\right]$. In the first 10-minute interval, compared to the hypoxic female, the hypoxic males travelled longer distances [by $79 \%, \mathrm{t}_{(72)}=4.89, \mathrm{p}<0.001$ ] and spent longer time in locomotion [by $95 \%, \mathrm{t}_{(72)}=3.67, \mathrm{p}<0.01$ ]. The main effect of time on rearing duration $\left[\mathrm{F}_{(5,72)}=20.5, \mathrm{p}<0.001\right]$ was confirmed. The effect of sex was close to being significant $\left[\mathrm{F}_{(1,72)}=3.78, \mathrm{p}=0.06\right]$, and the sex $\mathrm{x}$ time interaction was significant $\left[\mathrm{F}_{(5,72)}=2.66, \mathrm{p}<0.05\right]$. The hypoxic males reared more (by $77 \%$ ) than the hypoxic females in the first 10-minute interval $\left[\mathrm{t}_{(72)}=3.49, \mathrm{p}<0.01\right]$. Regarding the grooming duration, a significant effect of time $\left[\mathrm{F}_{(5,72)}=4.30\right.$, $\mathrm{p}<0.01]$ and a insignificant effect of $\operatorname{sex}\left[\mathrm{F}_{(1,72)}=2.67\right.$, $\mathrm{p}=0.11]$ was observed. Two-way ANOVA showed a significant interaction between these two factors $\left[\mathrm{F}_{(5,72)}=3.55, \mathrm{p}<0.01\right]$. The Bonferroni-corrected post hoc $t$-test revealed significantly lower grooming activity in the hypoxic females (by more than 8 times) than the hypoxic males between the $20^{\text {th }}$ and $30^{\text {th }}$ minute of the open field test $\left[\mathrm{t}_{(72)}=4.0, \mathrm{p}<0.001\right]$.

Sex differences in the behavior of rats following early postnatal hypoxia on PND9

Regarding sex differences in the distance travelled by the rats tested by the open field test on PND25, a significant effect of time $\left[\mathrm{F}_{(5,72)}=10.1, \mathrm{p}<0.001\right]$ and a significant time $x$ sex interaction $\left[\mathrm{F}_{(5,72)}=2.50\right.$, $\mathrm{p}<0.05]$ were found. However, the effect of sex was not significant $\left[\mathrm{F}_{(1,72)}=0.21, \mathrm{p}=0.65\right]$. Regarding the duration of 
locomotion, two-way ANOVA showed a significant effect of time $\left[\mathrm{F}_{(5,72)}=9.28, \mathrm{p}<0.001\right]$, but the effect of sex $\left[\mathrm{F}_{(1,72)}=0.09, \mathrm{p}=0.75\right]$ and the time $\mathrm{x}$ sex interaction $\left[\mathrm{F}_{(1,72)}=2.02, \mathrm{p}=0.09\right]$ were not significant.

Similar results were found regarding the duration of rearing and grooming in the rats. The main effect of time was found in both parameters [rearing: $\mathrm{F}_{(5,72)}=4.12$, $\mathrm{p}<0.05$; grooming: $\left.\mathrm{F}_{(5,72)}=3.25, \quad \mathrm{p}<0.05\right]$. Two-way ANOVA did not reveal a significant effect of either sex [rearing: $\mathrm{F}_{(1,72)}=0.26, \mathrm{p}=0.61$; grooming: $\mathrm{F}_{(1,72)}=0.76$, $\mathrm{p}=0.39$ ] or the sex $\mathrm{x}$ time interaction [rearing: $\mathrm{F}_{(5,72)}=2.32$, $p=0.05$; grooming: $\left.F_{(5,72)}=2.13, p=0.07\right]$. However, there was a tendency to reach significance, as seen in the $\mathrm{p}$ values.

The retesting of the animals on PND35 yielded the following results: only the factor of time was significant for each tested behavioral parameter [distance travelled: $\mathrm{F}_{(5,72)}=35.6, \mathrm{p}<0.001$; duration of locomotion: $\mathrm{F}_{(5,72)}=37.3, \mathrm{p}<0.001$; duration of rearing: $\mathrm{F}_{(5,72)}=29$, $\mathrm{p}<0.001$; and duration of grooming: $\left.\mathrm{F}_{(5,72)}=3.22, \mathrm{p}<0.05\right]$. The effect of sex and the sex $x$ time interaction were not statistically significant for any of the observed behavioral outcomes [distance travelled (sex: $\mathrm{F}_{(1,72)}=0.21, \mathrm{p}=0.65$; interaction: $\left.\mathrm{F}_{(5,72)}=1.28, \mathrm{p}=0.28\right)$; duration of locomotion (sex: $\mathrm{F}_{(1,72)}=0.22, \mathrm{p}=0.88$; interaction: $\mathrm{F}_{(5,72)}=1.07, \mathrm{p}=0.39$ ); duration of rearing (sex: $\mathrm{F}_{(1,72)}=1.18, \mathrm{p}=0.28$; interaction: $\left.\mathrm{F}_{(5,72)}=0.68, \mathrm{p}=0.64\right)$ and duration of grooming (sex: $\mathrm{F}_{(1,72)}=2.84, \mathrm{p}=0.096$; interaction: $\left.\mathrm{F}_{(5,72)}=0.41, \mathrm{p}=0.84\right)$ ].

\section{Histochemistry did not detect obvious morphological damage}

Histological evaluation was performed one and five days after hypoxia induction, and it did not demonstrate any obvious signs of neuronal degeneration or apoptosis. The same results were obtained by microscope analysis during adolescence (after the last open field test on PND35, Fig. 6).

\section{Discussion}

Severe and rapid hypobaric hypoxia is an extreme external condition that activates various physiological and pathophysiological homeostatic pathways (Virues-Ortega et al. 2004, Jayalakshmi et al. 2007, Zhang et al. 2018). It alters the neurochemistry of the brain, disrupts myelination during development and triggers both caspase-dependent and -independent pathways of cell death (Potter et al. 2018). The following
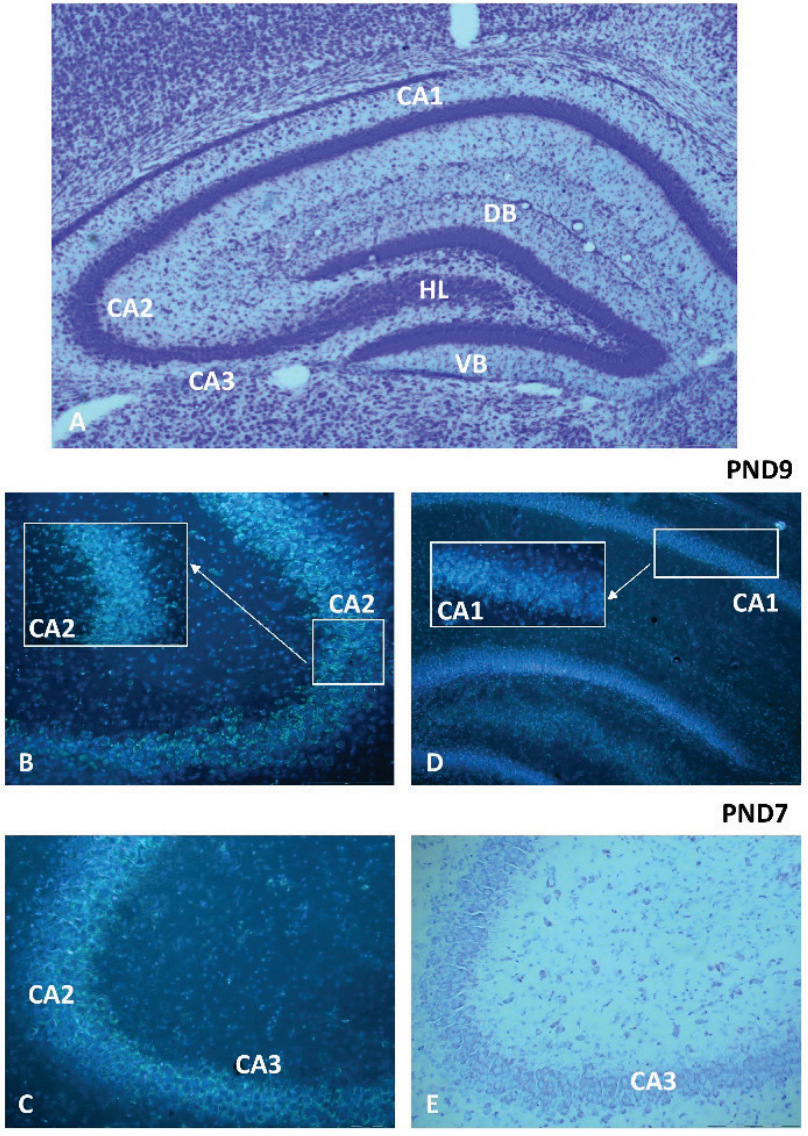

Fig. 6. Histological analyses performed on rat pups one and five days after hypoxia exposure. Hypoxia did not produce any visible morphological damage to the hippocampus. Panel A is a representative picture of the hippocampus of a control male rat perfused on PND12; Nissl staining; scale bar: $500 \mu \mathrm{m}$. Panel B is a representative picture of the CA2 region of the hippocampus of a rat exposed to hypoxia on PND9 and perfused on PND14; bisbenzimide staining; scale bar: $200 \mu \mathrm{m}$. Panel C is a representative picture of the CA2 and CA3 regions of the hippocampus in a rat exposed to hypoxia on PND7 and perfused on PND12; bisbenzimide staining; scale bar: $200 \mu \mathrm{m}$. Panel D is a representative picture of the CA1 region of the hippocampus and the hilus of the dentate gyrus in a rat exposed to hypoxia on PND9 and perfused on PND14; bisbenzimide staining; scale bar: $200 \mu \mathrm{m}$. Panel $E$ is a representative picture of the CA3 region of the hippocampus in a rat exposed to hypoxia on PND7 and perfused on PND12; Nissl staining; scale bar: $500 \mu \mathrm{m}$.

four major questions were addressed in this study: 1) what is the effect of hypoxia exposure on PND7 and PND9; 2) is this two-day shift in hypoxia exposure capable of causing different behavioral consequences in later life?; 3) what part of these behavioral changes can be ascribed to sex-related differences?; and 4) is hypobaric hypoxia alone able to induce structural damage to the hippocampus? Our model of hypoxia simulating an altitude of $9000 \mathrm{~m}$ did not induce any detectable morphological changes in the rat hippocampus. Ipsilateral damage to the brain, as described by the so-called Rice- 
Vannucci model, requires the surgical ligation of the carotid artery i.e. ischemia, followed by normobaric hypoxia to induce structural damage (Vannucci 1990). As our experimental model included only hypoxia, we did not confirm any neurodegeneration within the examined areas of the brain. On the other hand, the same hypoxic insult was capable of influencing the spontaneous behavior of the rats in later life. Such morphological and functional discrepancies are interesting for two reasons. First, subtle changes in spontaneous behavior, which are not accompanied by structural alterations, highlight a more realistic clinical picture of mild perinatal hypoxic damage. However, it is not excluded that one of the perinatal hypoxia consequence is sex specific modification of some behavioral domains i.e. willingness to explore or immobility, without any obvious changes in the morphology of the brain. Second, the model indicates the importance of behavioral testing related to hypoxia exposure. Exposure to one-hour hypoxia $(9000 \mathrm{~m})$ is lethal to adult rats but not to immature PND7 and PND9 pups of both sexes. Immature brain tissue, unlike adult brain tissue, can withstand a significant period of oxygen deprivation because it requires less metabolic fuel (glucose plays only a minor role) (Nehlig et al. 1993). On the other hand, if a critical point of energy deprivation is reached, immature nervous tissue is more prone to excitotoxic damage (Doble 1999, Riljak et al. 2016). PND7 rats most closely approximate 30-32 weeks of gestation, while PND9-PND12 is representative of gestational weeks 40-42. There are substantial differences in brain development between PND7 and PND9. Myelination along with synaptogenesis occur in a relatively conserved pattern (Volpe 2000). In addition, white matter is more vulnerable as compared to grey matter and oligodendrocyte maturation is not yet presented in the PND7 (Volpe 2003, Hagberg et al. 2002). Another very important difference is presented in GABA signalling. The activation of the $\mathrm{GABA}_{\mathrm{A}}$ receptor in immature neurons triggers excessive excitation and thus might determine or even limit the neuronal differentiation (Ben-Ari et al. 2012). Hypoxia induced on PND7 was also recognized as a significant factor triggering the process of epileptogenesis. Moreover, there is dramatic decrease in postsynaptic densities of glutamate receptor associated with increased vulnerability to white matter injury in the developing brain (Shen et al. 2012). Hypoxia exposed rats suffer from synaptic transmission disturbances and changes in dendritic spine physiology and morphology. Such synapse-related changes are framed by the changed postsynaptic glutamate sensitivity and probably by different amount of released glutamate (Shen et al. 2012, Zhuravin et al. 2019).

Rats exposed to hypoxia on PND7 mainly exhibit changes in horizontal (locomotion) and vertical (rearing) activity, while only grooming is affected in rats exposed to hypoxia on PND9 (Volpe 2001, Hill et al. 2011). Hypoxia-related motor impairments may influence the ability to execute a specific task and to explore the environment of the experimental arena in a genderdependent manner (Arteni et al. 2010, Peterson et al. 2015, Sanches et al. 2015, Huang et al. 2016). Newborn rodents express the same brain development characteristics (partially completed neurogenesis of specific brain areas and the initialization of myelination) as preterm infants (Romijn et al. 1991, Towfighi et al. 1997, Zhu et al. 2005, Cuaycong et al. 2011). Hypoxia interferes with neural proliferation in a sex-dependent manner (Mayoral et al. 2009). Male sex is a significant risk factor for worse neurocognitive outcomes of preterm delivery. Furthermore, neuroprotective treatments are less effective in males (Lan et al. 2011). The mechanisms of such gender-dependent differences in brain vulnerability are not known yet. There are a number of mechanisms to play a key role in hypoxia-ischemia brain injury due to their different impacts on mitochondrial function and their different antioxidant capacities, inflammatory responses and microglial activation abilities in males and females (Mayoral et al. 2009). The hypoxia-ischemiainduced loss of volume in specific areas of the brain and changes in the progression of myelinization are likely hormonally related (Netto et al. 2017). Estrogen and testosterone interfere with the susceptibility of the brain to hypoxia-induced damage in an age-dependent manner (Hill et al. 2012). In our study, male rats exposed to hypoxia on PND7 exhibited a continuous decline in moved distance, locomotion and rearing duration throughout the one-hour period, suggesting a normal profile of the habituation when exposed to the new environment. However, rats exposed to hypoxia on PND9 did not show the same decline in the observed behavioral parameters during the one-hour period, suggesting a potential inability to cope with a novel environment. The difference between the time spent rearing and the time in locomotion on PND25 and PND35 may be explained by the different levels of cortical vs. subcortical structural maturity. In contrast, the lower intensity of locomotion and rearing of the females was first 
noticeable on PND35. This may be ascribed to all of the abovementioned hormonal and non-hormonal mechanisms. All the effects mentioned above are strictly functional, as we did not prove neurodegeneration.

What is surprising, however, is the disproportionate effect of exposure to higher-severity hypoxia on PND7 compared to PND9. The rat pups were more vulnerable, and the effect of hypoxia at this stage of development was long-lasting. Males in general showed higher sensitivity to this insult. Both, males and females postnatally exposed to hypoxia exhibited higher rearing activity. However, in females it reached statistical significance, while in males not. Moreover, the process of habituation was clearly disrupted in both, males and females. Males never decreased the rearing activity, while the females did (but clearly much later than control counterparts). It seems that hypoxia interferes with the capacity of unconditional learning processes. The interpretation of self-grooming data is not easy, as it might represent many behavioral aspects of the particular animal (Estanislau et al. 2013, Estanislau et al. 2019). The findings of the present study confirm complexity of the self-grooming behavior, since hypoxia induced on PND7 resulted in alteration of the grooming pattern not sooner than PND35 and this change was sex-dependent. If animals were exposed to hypoxia on PND9, the grooming profile changed already at PND25, however, it returned back to the profile of control animals on PND35. The present study suggests that the relationship between grooming and hypoxia deserves more attention in future.

In conclusion, hypobaric hypoxia is capable of inducing significant behavioral changes in rat pups when applied on PND7 and PND9. The injury was more severe on PND7 and predominantly affected the males. Hypoxia was able to modify the behavioral profile in terms of habituation and the ability of rats to cope with novelty. No structural changes were observed in the hippocampus. The observed changes in the spontaneous behavior of the rats were not accompanied by even subtle morphological changes. This study highlights the necessity of including both genders in future hypoxia studies. However, our study has some limitations. Hypoxia exposition took place for one hour only, so was relatively short-term. Secondly, other than $9000 \mathrm{~m}$ simulated altitude might bring another behavioral outcome (so might do various mutual combinations altitude vs. time of exposure). Future studies may aim to elucidate the different sensitivities and reactivities of the neuronal tissue of males and females to hypoxia exposure and may allow us to formulate specific therapeutic strategies for ameliorating or even preventing the effects of hypoxia.

\section{Conflict of Interest}

There is no conflict of interest.

\section{Acknowledgements}

The authors thank $K$. Janišová for her technical assistance. This study was supported by the Charles University Grant Agency (grant 454218) and the research programs PROGRES Q35 and PROGRES Q25 by Charles University.

\section{References}

ARTENI NS, PEREIRA LO, RODRIGUES AL, LAVINSKY D, ACHAVAL ME, NETTO CA: Lateralized and sexdependent behavioral and morphological effects of unilateral neonatal cerebral hypoxia-ischemia in the rat. Behav Brain Res 210: 92-98, 2010. https://doi.org/10.1016/j.bbr.2010.02.015

ARUMUGAM TV, BAIK SH, BALAGANAPATHY P, SOBEY CG, MATTSON MP, JO DG: Notch signaling and neuronal death in stroke. Prog Neurobiol 165-167: 103-116, 2018. https://doi.org/10.1016/j.pneurobio.2018.03.002

BERGER R, GARNIER Y, JENSEN A: Perinatal brain damage: underlying mechanisms and neuroprotective strategies. J Soc Gynecol Investig 9: 319-328, 2002. https://doi.org/10.1177/107155760200900601

BISWAL S, SHARMA D, KUMAR K, NAG TC, BARHWAL K, HOTA SK, KUMAR B: Global hypoxia induced impairment in learning and spatial memory is associated with precocious hippocampal aging. Neurobiol Learn Mem 133: 157-170, 2016. https://doi.org/10.1016/j.nlm.2016.05.011

BOGDANOVA OV, ABDULLAH O, KANEKAR S, BOGDANOV VB, PRESCOT AP, RENSHAW PF: Neurochemical alterations in frontal cortex of the rat after one week of hypobaric hypoxia. Behav Brain Res 263: 203-209, 2014. https://doi.org/10.1016/j.bbr.2014.01.027 
BONA E, HAGBERG H, LOBERG EM, BAGENHOLM R, THORESEN M: Protective effects of moderate hypothermia after neonatal hypoxia-ischemia: short- and long-term outcome. Pediatr Res 43: 738-745, 1998. https://doi.org/10.1203/00006450-199806000-00005

CARTY ML, WIXEY JA, KESBY J, REINEBRANT HE, COLDITZ PB, GOBE G, BULLER KM: Long-term losses of amygdala corticotropin-releasing factor neurons are associated with behavioural outcomes following neonatal hypoxia-ischemia. Behav Brain Res 208: 609-618, 2010. https://doi.org/10.1016/j.bbr.2010.01.007

CLANCY B, DARLINGTON RB, FINLAY BL: Translating developmental time across mammalian species. Neuroscience 105: 7-17, 2001. https://doi.org/10.1016/S0306-4522(01)00171-3

COSTELOE K, HENNESSY E, GIBSON AT, MARLOW N, WILKINSON AR: The EPICure study: outcomes to discharge from hospital for infants born at the threshold of viability. Pediatrics 106: 659-671, 2000. https://doi.org/10.1542/peds.106.4.659

CUAYCONG M, ENGEL M, WEINSTEIN SL, SALMON E, PERLMAN JM, SUNDERAM S, VANNUCCI SJ: A novel approach to the study of hypoxia-ischemia-induced clinical and subclinical seizures in the neonatal rat. Dev Neurosci 33: 241-250, 2011. https://doi.org/10.1159/000331646

DOBLE A: The role of excitotoxicity in neurodegenerative disease: implications for therapy. Pharmacol Ther 81: 163-221, 1999. https://doi.org/10.1016/S0163-7258(98)00042-4

DONDERS J, HOFFMAN NM: Gender differences in learning and memory after pediatric traumatic brain injury. Neuropsychology 16: 491-499, 2002. https://doi.org/10.1037//0894-4105.16.4.491

ESTANISLAU C, DIAZ-MORAN S, CANETE T, BLAZQUEZ G, TOBENA A, FERNANDEZ-TERUEL A: Contextdependent differences in grooming behavior among the NIH heterogeneous stock and the Roman high- and low-avoidance rats. Neurosci Res 77: 187-201, 2013. https://doi.org/10.1016/j.neures.2013.09.012

ESTANISLAU C, VELOSO AWN, FILGUEIRAS GB, MAIO TP, DAL-COL MLC, CUNHA DC, KLEIN R, CARMONA LF, FERNANDEZ-TERUEL A: Rat self-grooming and its relationships with anxiety, dearousal and perseveration: Evidence for a self-grooming trait. Physiol Behav 209: 112585, 2019. https://doi.org/10.1016/i.physbeh.2019.112585

GINET V, SPIEHLMANN A, RUMMEL C, RUDINSKIY N, GRISHCHUK Y, LUTHI-CARTER R, CLARKE PG, TRUTTMANN AC, PUYAL J: Involvement of autophagy in hypoxic-excitotoxic neuronal death. Autophagy 10: 846-860, 2014. https://doi.org/10.4161/auto.28264

HILL CA, ALEXANDER ML, MCCULLOUGH LD, FITCH RH: Inhibition of X-linked inhibitor of apoptosis with embelin differentially affects male versus female behavioral outcome following neonatal hypoxia-ischemia in rats. Dev Neurosci 33: 494-504, 2011. https://doi.org/10.1159/000331651

HILL CA, FITCH RH: Sex differences in mechanisms and outcome of neonatal hypoxia-ischemia in rodent models: implications for sex-specific neuroprotection in clinical neonatal practice. Neurol Res Int 2012: 867531, 2012. https://doi.org/10.1155/2012/867531

HUANG HZ, WEN XH, LIU H: Sex differences in brain MRI abnormalities and neurodevelopmental outcomes in a rat model of neonatal hypoxia-ischemia. Int $\mathrm{J}$ Neurosci 126: 647-657, 2016. https://doi.org/10.3109/00207454.2015.1047016

CHEN PZ, HE WJ, ZHU ZR, E GJ, XU G, CHEN DW, GAO YQ: Adenosine A2A receptor involves in neuroinflammation-mediated cognitive decline through activating microglia under acute hypobaric hypoxia. Behav Brain Res 347: 99-107, 2018. https://doi.org/10.1016/j.bbr.2018.02.038

JAYALAKSHMI K, SINGH SB, KALPANA B, SAIRAM M, MUTHURAJU S, ILAVAZHAGAN G: N-acetyl cysteine supplementation prevents impairment of spatial working memory functions in rats following exposure to hypobaric hypoxia. Physiol Behav 92: 643-650, 2007. https://doi.org/10.1016/j.physbeh.2007.05.051

LAN WC, PRIESTLEY M, MAYORAL SR, TIAN L, SHAMLOO M, PENN AA: Sex-specific cognitive deficits and regional brain volume loss in mice exposed to chronic, sublethal hypoxia. Pediatr Res 70: 15-20, 2011. https://doi.org/10.1203/PDR.0b013e31821b98a3

LAUTERBACH MD, RAZ S, SANDER CJ: Neonatal hypoxic risk in preterm birth infants: the influence of sex and severity of respiratory distress on cognitive recovery. Neuropsychology 15: 411-420, 2001. https://doi.org/10.1037//0894-4105.15.3.411 
MAYORAL SR, OMAR G, PENN AA: Sex differences in a hypoxia model of preterm brain damage. Pediatr Res 66: 248-253, 2009. https://doi.org/10.1203/PDR.0b013e3181b1bc34

NEHLIG A, PEREIRA DE VASCONCELOS A: Glucose and ketone body utilization by the brain of neonatal rats. Prog Neurobiol 40: 163-221, 1993. https://doi.org/10.1016/0301-0082(93)90022-K

NETTO CA, SANCHES E, ODORCYK FK, DURAN-CARABALI LE, WEIS SN: Sex-dependent consequences of neonatal brain hypoxia-ischemia in the rat. J Neurosci Res 95: 409-421, 2017. https://doi.org/10.1002/jnr.23828

NYAKAS C, BUWALDA B, LUITEN PG: Hypoxia and brain development. Prog Neurobiol 49: 1-51, 1996. https://doi.org/10.1016/0301-0082(96)00007-X

PAPPAS A, SHANKARAN S, MCDONALD SA, VOHR BR, HINTZ SR, EHRENKRANZ RA, TYSON JE, YOLTON K, DAS A, BARA R, HAMMOND J, HIGGINS RD: Cognitive outcomes after neonatal encephalopathy. Pediatrics 135: e624-e634, 2015. https://doi.org/10.1542/peds.2014-1566

PETERSON BL, WON S, GEDDES RI, SAYEED I, STEIN DG: Sex-related differences in effects of progesterone following neonatal hypoxic brain injury. Behav Brain Res 286: 152-165, 2015. https://doi.org/10.1016/j.bbr.2015.03.005

POTTER M, ROSENKRANTZ T, FITCH RH: Behavioral and neuroanatomical outcomes in a rat model of preterm hypoxic-ischemic brain injury: Effects of caffeine and hypothermia. Int J Dev Neurosci 70: 46-55, 2018. https://doi.org/10.1016/j.ijdevneu.2018.02.001

RAZ S, LAUTERBACH MD, HOPKINS TL, GLOGOWSKI BK, PORTER CL, RIGGS WW, SANDER CJ: A female advantage in cognitive recovery from early cerebral insult. Dev Psychol 31: 958, 1995. https://doi.org/10.1037/0012-1649.31.6.958

RILJAK V, KRAF J, DARYANANI A, JIRUSKA P, OTAHAL J: Pathophysiology of perinatal hypoxic-ischemic encephalopathy - biomarkers, animal models and treatment perspectives. Physiol Res 65: S533-S545, 2016.

RILJAK V, MARESOVA D, POKORNY J: Nicotine effects on rat seizures susceptibility and hippocampal neuronal degeneration. Neuro Endocrinol Lett 31: 792-795, 2010.

RILJAK V, MILOTOVA M, JANDOVA K, POKORNY J, LANGMEIER M: Morphological changes in the hippocampus following nicotine and kainic acid administration. Physiol Res 56: 641-649, 2007.

ROMIJN HJ, HOFMAN MA, GRAMSBERGEN A: At what age is the developing cerebral cortex of the rat comparable to that of the full-term newborn human baby? Early Hum Dev 26: 61-67, 1991. https://doi.org/10.1016/0378-3782(91)90044-4

SANCHES EF, ARTENI N, NICOLA F, ARISTIMUNHA D, NETTO CA: Sexual dimorphism and brain lateralization impact behavioral and histological outcomes following hypoxia-ischemia in P3 and P7 rats. Neuroscience 290: 581-593, 2015. https://doi.org/10.1016/j.neuroscience.2014.12.074

SARNAT HB, SARNAT MS: Neonatal encephalopathy following fetal distress. A clinical and electroencephalographic study. Arch Neurol 33: 696-705, 1976. https://doi.org/10.1001/archneur.1976.00500100030012

SEMPLE BD, BLOMGREN K, GIMLIN K, FERRIERO DM, NOBLE-HAEUSSLEIN LJ: Brain development in rodents and humans: Identifying benchmarks of maturation and vulnerability to injury across species. Prog Neurobiol 106-107: 1-16, 2013. https://doi.org/10.1016/j.pneurobio.2013.04.001

SHEN Y, LIU XB, PLEASURE DE, DENG W: Axon-glia synapses are highly vulnerable to white matter injury in the developing brain. J Neurosci Res 90: 105-121, 2012. https://doi.org/10.1002/jnr.22722

TOWFIGHI J, MAUGER D, VANNUCCI RC, VANNUCCI SJ: Influence of age on the cerebral lesions in an immature rat model of cerebral hypoxia-ischemia: a light microscopic study. Brain Res Dev Brain Res 100: 149-160, 1997. https://doi.org/10.1016/S0165-3806(97)00036-9

VAN DE WEERD HA, BULTHUIS RJ, BERGMAN AF, SCHLINGMANN F, TOLBOOM J, VAN LOO PL, REMIE R, BAUMANS V, VAN ZUTPHEN LF: Validation of a new system for the automatic registration of behaviour in mice and rats. Behav Processes 53: 11-20, 2001. https://doi.org/10.1016/S0376-6357(00)00135-2

VANNUCCI RC: Experimental biology of cerebral hypoxia-ischemia: relation to perinatal brain damage. Pediatr Res 27: 317-326, 1990. https://doi.org/10.1203/00006450-199004000-00001

VIRUES-ORTEGA J, BUELA-CASAL G, GARRIDO E, ALCAZAR B: Neuropsychological functioning associated with high-altitude exposure. Neuropsychol Rev 14: 197-224, 2004. https://doi.org/10.1007/s11065-004-8159-4 
VOLPE JJ: Perinatal brain injury: from pathogenesis to neuroprotection. Ment Retard Dev Disabil Res Rev 7: 56-64, 2001. https://doi.org/10.1002/1098-2779(200102)7:1<56::AID-MRDD1008>3.0.CO;2-A

ZAYACHKIVSKY A, LEHMKUHLE MJ, EKSTRAND JJ, DUDEK FE: Ischemic injury suppresses hypoxia-induced electrographic seizures and the background EEG in a rat model of perinatal hypoxic-ischemic encephalopathy. J Neurophysiol 114: 2753-2763, 2015. https://doi.org/10.1152/jn.00796.2014

ZHANG XY, ZHANG XJ, XV J, JIA W, PU XY, WANG HY, LIANG H, ZHUOMA L, LU DX: Crocin attenuates acute hypobaric hypoxia-induced cognitive deficits of rats. Eur J Pharmacol 818: 300-305, 2018. https://doi.org/10.1016/j.ejphar.2017.10.042

ZHU C, WANG X, XU F, BAHR BA, SHIBATA M, UCHIYAMA Y, HAGBERG H, BLOMGREN K: The influence of age on apoptotic and other mechanisms of cell death after cerebral hypoxia-ischemia. Cell Death Differ 12: 162-176, 2005. https://doi.org/10.1038/sj.cdd.4401545

ZHURAVIN IA, DUBROVSKAYA NM, VASILEV DS, POSTNIKOVA TY, ZAITSEV AV: Prenatal hypoxia produces memory deficits associated with impairment of long-term synaptic plasticity in young rats. Neurobiol Learn Mem 164: 107066, 2019. https://doi.org/10.1016/j.nlm.2019.107066 